needs to be done with great diligence for the same reason $[2,3,8]$. The difficulties in obtaining a correct histopathologic grading as well as the premalignant potential of $\mathrm{MCN}$ has been considered arguments for radical resection of all MCN [2,3,7]. Regarding the prognosis, early studies reported 5-year survival rates exceeding $50 \%$, but these figures may be somewhat overestimated due to an insufficient histopathologic grading [8]. In fact, malignant MCN with invasion seem to have a survival only slightly better than ductal adenocarcinoma, while long-term survival is the rule after resection of benign and borderline MCN [2-4].

To summarize, we report the unusual case of a perforated MCN as the cause of pancreatic ascites. The case illustrates that a pancreatic neoplasm with ascites does not equal peritoneal carcinomatosis or a locally advanced tumour. Examination of ascites fluid for amylase and cytology should be done in these cases.

\section{References}

[1] Chebli JM, Gaburri PD, de Souza AF, Ornellas AT, Martins Junior EV, Chebli LA, et al. Internal pancreatic fistulas:
Proposal of a management algorithm based on a case series analysis. J Clin Gastroenterol 2004;38:795-800.

[2] Sarr MG, Carpenter HA, Prabhakar LP, Orchard TF, Hughes $\mathrm{S}$, van Heerden JA, et al. Clinical and pathologic correlation of 84 mucinous cystic neoplasms of the pancreas: Can one reliably differentiate benign from malignant (or premalignant) neoplasms? Ann Surg 2000;231:205-12.

[3] Zamboni G, Scarpa A, Bogina G, Iacono C, Bassi C, Talamini $\mathrm{G}$, et al. Mucinous cystic tumors of the pancreas: Clinicopathological features, prognosis, and relationship to other mucinous cystic tumors. Am J Surg Pathol 1999;23:410-22.

[4] Wilentz RE, Albores-Saavedra J, Zahurak M, Talamini MA, Yeo CJ, Cameron JL, et al. Pathologic examination accurately predicts prognosis in mucinous cystic neoplasms of the pancreas. Am J Surg Pathol 1999;23:1320-7.

[5] Kosmahl M, Pauser U, Peters K, Sipos B, Luttges J, Kremer $\mathrm{B}$, et al. Cystic neoplasms of the pancreas and tumor-like lesions with cystic features: A review of 418 cases and a classification proposal. Virchows Arch 2004;445:168-78.

[6] Le Borgne J, de Calan L, Partensky C. Cystadenomas and cystadenocarcinomas of the pancreas: A multiinstitutional retrospective study of 398 cases. French Surgical Association. Ann Surg 1999;230:152-61.

[7] Rattner DW, Fernandez-del Castillo C, Warshaw AL. Cystic pancreatic neoplasms. Ann Oncol 1999;10(Suppl 4):104-6.

[8] Siech M, Tripp K, Schmidt-Rohlfing B, Mattfeldt T, Widmaier U, Gansauge F, et al. Cystic tumours of the pancreas: Diagnostic accuracy, pathologic observations and surgical consequences. Langenbecks Arch Surg 1998;383:56-61.

\title{
A case of Adult T-cell leukemia/lymphoma (ATL) with a survival of more than 13 years
}

\section{ACHILÉA L. BITTENCOURT ${ }^{1}$, HELENEMARIE S. BARBOSA ${ }^{1}$, ALEX PIMENTA $^{2}$ \& LOURDES FARRE ${ }^{3}$}

${ }^{1}$ Department of Pathology, Professor Edgard Santos Teaching Hospital, Federal University of Bahia, Salvador, Bahia, Brazil, ${ }^{2}$ Multidisciplinary Oncology Care Clinic, Salvador, Bahia, Brazil, and ${ }^{3}$ Laboratory of Experimental Pathology (LAPEX), CPqGM-FIOCRUZ, Salvador, Bahia, Brazil

\section{To the Editor}

Adult T-cell leukemia/lymphoma (ATL) is an aggressive type of leukemia/lymphoma associated with the human T-cell lymphotropic virus type I (HTLV-I). ATL is characterized by a short survival time, a poor response to chemotherapy and is usually reported in adults, the mean age of onset being around 58 years. It is classically classified into four clinical types: acute, chronic, lymphoma, and smol- dering [1]. We report an unusual case with a very prolonged survival time.

A 27-year-old black man was first examined in November 1991 with a history of skin lesions that started when he was 24 years of age. He was breastfed for 3 years. Both the patient and his mother were HTLV-I + and HIV - . Dermatological examination revealed infiltrated plaques on his back and nose. Physical examination, blood cell counts, blood levels of calcium and lactate dehydrogenase (LDH), chest $\mathrm{x}$-ray and abdominal ultrasound were all normal. A Tcell lymphoma was diagnosed in a skin biopsy. In

Correspondence: Achiléa L. Bittencourt, Serviço de Anatomia Patológica, Hospital Universitário Prof. Edgard Santos (HUPES), Rua Augusto Viana s/n-Canela-40110-160, Salvador, Bahia, Brasil. Tel/Fax: +55 71 33396335. E-mail: achilea@uol.com.br. 
1994, the lesions became more infiltrated. At this time, he had mild lymphocytosis (5.700 lymphocytes $/ \mathrm{mm}^{3}$ ), a LDH blood level twice the normal value and no hypercalcemia or infiltration of internal organs. After four cycles of Cyclophosphamide, Adriamycin, Vincristine, and Prednison, regression of the skin lesions was observed. In September 1995, after progression of the skin lesions, treatment with IFN- $\alpha$ ( 5 millions IU 3 times a week) and zidovudine (AZT), $300 \mathrm{mg}$ per day was initiated until September 1997, with complete remission. Ten months later the patient developed new facial lesions that were treated with IFN- $\alpha$ ( 5 millions IU 3 times a week) plus AZT $(500 \mathrm{mg} /$ day); besides, radiotherapy was used on the larger lesions. In March 2001 the patient developed cervical lymphadenopathy, a supraglottic lesion, shallow ulcerations in the thighs (Figure 1), and in the scrotum and tumors in the face. Treatment with IFN- $\alpha / \mathrm{AZT}$ was interrupted and chemotherapy was introduced with no response. The patient was again treated with radiotherapy and the lesions were brought under control. In November 2002, he presented a relapse of the oral lesion, and the combination of IFN- $\alpha / \mathrm{AZT}$ was resumed. In May 2004, after an increase in the blood levels of liver transaminases the treatment with IFN- $\alpha /$ AZT was discontinued. In August 2005, the lesions progressed significantly many of them with ulceration determining the reiniciation of treatment with IFN- $\alpha / \mathrm{AZT}$ until November, when he was admitted to the hospital complaining of malaise, headache and coughing. His condition rapidly deteriorated. A CT scan revealed extensive cerebral hemorrhage. Examination of cerebrospinal fluid was negative for lymphoma. Despite surgical drainage and intensive clinical care, the patient died. As it refers to laboratory results calcium levels remained normal throughout the evolution of the disease and LDH levels were

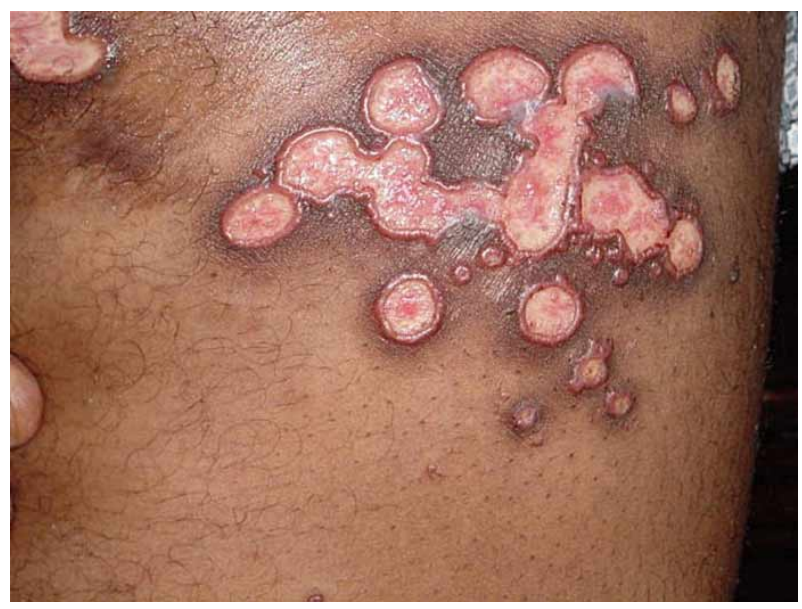

Figure 1. Shallow ulcerations with infiltrated borders that appeared after the evolution to the chronic form of the disease. twice the normal level. After March 2003 LDH levels began to increase reaching more than three times the normal value. Lymphocytosis increased between April 2004 until the patient died, varying from 8.000 to 9.300 lymphocytes $/ \mathrm{mm}^{3}$. Apart from the oral mucosa and the skin, no other sites of infiltration were found. Monoclonal integration of HTLV-I was detected in peripheral blood mononuclear cells (PBMC) by long and inverse PCR [2]. The skin biopsy performed in 1991 showed a dense infiltration of small and medium pleomorphic cells in the upper dermis. In other two skin biopsies performed in 1994 and 2001 there was a diffuse infiltration of the dermis by medium-sized cells with few large cells. Sparse multinucleated giant cells with pleomorphic nuclei were seen in all the skin biopsies (Figure 2). The atypical lymphocytes were positive for CD45RO, CD3, CD4, CD5, and CD25 and were negative for CD7, CD8, CD30, CD20, and CD79a. The proliferative index evaluated by $\mathrm{Ki}-67$ varied from $5 \%$ to $25 \%$ in the last biopsy.

The diagnosis of ATL was based on a positive serology for HTLV-I plus the histopathological and immunohistochemical features and the presence of monoclonal integrated HTLV-I provirus in the DNA of PBMC.

This case at first was classified as smoldering ATL, but after 3 years of disease he developed the characteristics of the chronic type of ATL. It is interesting to note that, in this case, the disease remained localized in the skin for many years, even in the chronic phase. The chronic type of ATL has a median survival time (MST) of around 2 years [1] but the MST of the smoldering type is longer [3]. At any rate, a survival of more than 13 years, as occurred in the present case, is very atypical even for smoldering ATL, especially considering that this

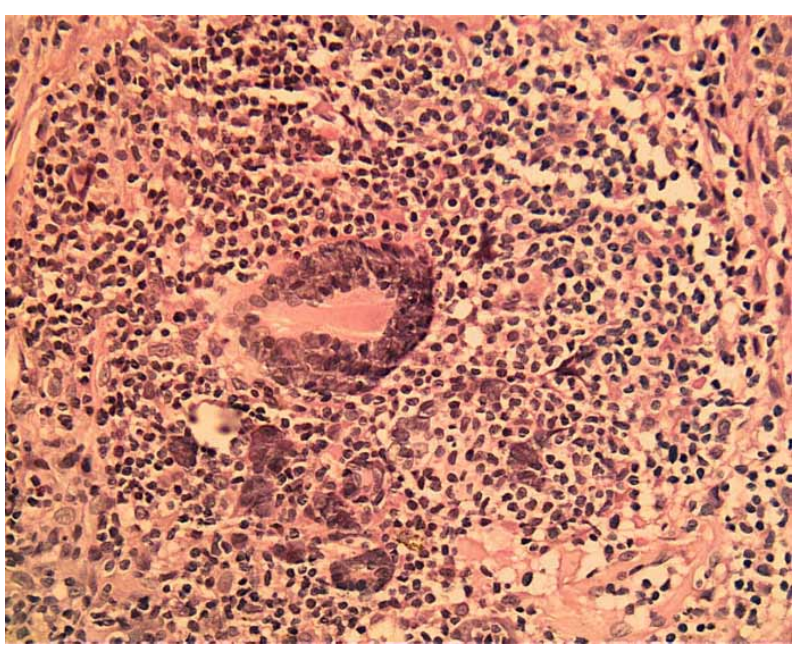

Figure 2. Multinucleated giant cells with pleomorphic nuclei. HE, X 250. 
patient evolved to the chronic form of the disease after 3 years and died more than 10 years later. Probably the treatment with IFN- $\alpha / \mathrm{AZT}$, albeit intermittently, contributed to the patient's prolonged survival, since the lesions responded every time it was used. Recently, this treatment was used in four cases of chronic ATL with complete response in two cases [4]. The death of this patient was caused by intracerebral hemorrhage, and was not directly linked to ATL. Recently, the possibility that hemorrhage could be a side-effect of IFN- $\alpha$ during therapy or in the post-treatment period has been raised [5]. Another unusual clinical aspect of the present case was the occurrence of shallow cutaneous ulcerations with infiltrated borders, which is unusual in ATL.

The presence of multinucleated giant cells in ATL has been previously described [6] however in the present case the multinucleated giant cells had atypical nuclei, a histological aspect that has not been previously observed.

This case consists of an early manifestation of ATL since the average age of onset is over 48 years in Brazil [3]. The patient most probably acquired the infection through prolonged breast-feeding, since his mother was seropositive and he had no history of blood transfusion. It is known that HTLV-I vertical transmission is directly proportional to the time of breastfeeding [7]. In conclusion, this is a case of ATL in a young adult with distinct clinical and histological manifestations and a prolonged survival time.

\section{Acknowledgements}

The authors are grateful to Dr Johan Van Weyenbergh and to Dr Anne-Mieke Vandamme for their contribution to this study. This work was supported by the Conselho Nacional de Pesquisa (CNPq) and Fundação de Apoio à Pesquisa do Estado da Bahia (FAPESB). The present study was approved by the Institutional Review Board of the Teaching Hospital of the Federal University of Bahia.

\section{References}

[1] Shimoyama, $M$ and Members of the Lymphoma Study Group. Diagnostic criteria and classification of clinical subtypes of adult T-cell leukaemia-lymphoma. A report from the Lymphoma Study Group (1984-87). Brit J Haematol 1991;79:428-37.

[2] Etoh K, Tamiya S, Yamaguchi K, Okayama A, Tsubouchi H, Ideta $\mathrm{T}$, et al. Persistent clonal proliferation of human T-lymphotropic virus type I-infected cells in vivo. Cancer Res 1997;57:4862-7.

[3] Bittencourt AL, Vieira MG, Brites C, Farre L, Barbosa HS. Adult T-cell leukemia/lymphoma (ATL) in Bahia, Brazil: Analysis of prognostic factors in a group of 70 patients. Amer J Clin Pathol 2007;128:875-82.

[4] Kchour G, Makhoul NJ, Mahmoudi M, Kooshyar MM, Shirdel A, Rastin $M$, et al. Zidovudine and interferon- $\alpha$ treatment induces a high response rate and reduces HTLV-I proviral load and VEGF plasma levels in patients with adult Tcell leukemia from North East Iran. Leuk Lymphoma 2007; 48:330-6.

[5] Ferencz S, Batey R. Intracerebral haemorrhage and hepatitis C treatment. J Viral Hepat 2003;10:401-3.

[6] Bittencourt AL, Barbosa HS, Requião C, Silva AC, Vandamme AM, Van Weyenbergh J, et al. An exceptional pediatric case of ATL with a mixed $\mathrm{CD} 4+$ and $\mathrm{CD} 8+$ phenotype and a particularly indolent course. J Clin Oncol 2007;10:2480-2.

[7] Oki T, Yoshinaga M, Otsuka H, Miyata K, Sonoda S, Nagata Y. A sero-epidemiological study on mother-to-child transmission of HTLV-I in Southern Kyushu, Japan. Asia Oceania J Obstet Gynaecol 1992;18:371-7.

\title{
Hypertrophic osteoarthropathy leading to the diagnosis of primitive neuroectodermal tumour (PNET)
}

\author{
CONLETH MURPHY ${ }^{1}$, MOHD SYAHIZUL NUHAIRY MOHD SHARIAL ${ }^{1}$, \\ NEIL BRENNAN ${ }^{2}$, GARRY LEE ${ }^{3}$, EUGENE MOYLAN ${ }^{1}$ \& SEAMUS O’ REILLY ${ }^{1}$ \\ ${ }^{1}$ Department of Medical Oncology, Mercy University Hospital, Cork, Ireland, ${ }^{2}$ Department of Respiratory Medicine, Mercy \\ University Hospital, Cork, Ireland, and ${ }^{3}$ Department of Pathology, Mercy University Hospital, Cork, Ireland
}

Correspondence: Conleth Murphy, Department of Medical Oncology, Mercy University Hospital, Cork, Ireland. Tel: +353 872078178 . E-mail: conlethmurphy@gmail.com 